\title{
Excessive scarring as a consequence of healing
}

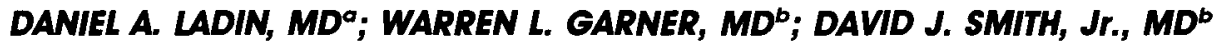

\begin{abstract}
Synthesis and degradation of collagen is an essential component of wound healing. In most persons, this deposition of collagen results in the formation of a fine line scar which restores much of the tensile strength to the injured tissue and is cosmetically acceptable. However, in certain individuals, the result of wound healing is the excessive accumulation of collagen, resulting in a hypertrophic scar or keloid. The precise origin of this abnormal collagen deposition is unknown, but recent studies have begun to identify potential mechanisms for these disfiguring and painful lesions. This article will review the clinical and laboratory findings pertinent to understanding the origin and treatment of excessive scarring. (WOUND REP REG 1995;3:6-14)
\end{abstract}

Growth, regeneration, and repair are a continuum of processes which form new tissue. During human embryogenesis and fetal wound healing, dividing layers of cells coalesce to form discrete organs and tissues. Tissues formed in this manner increase in size while maintaining their unique architecture. In adults, the liver and muscle retain this ability to increase tissue mass and regenerate through cell division. Those tissues formed by regeneration are indistinguishable from adjacent normal tissue. In contrast, healing of most tissue defects is by repair and is easily identifiable by the formation of scar.

Normal wound healing comprises a mixture of regeneration and repair and is a highly regulated cascade of events. Cells respond to the disruption of their environment by the release of mediators which stimulate chemotaxis, cellular proliferation, and the deposition of extracellular matrix proteins. Typically in

From the Division of Plastic Surgery, Henry Ford Hospital, Detroita; and the Section of Plastic and Reconstructive Surgery, University of Michigan, Ann Arbor, ${ }^{\circ}$ Mich.

Reprint requests: Daniel Ladin, MD, Henry Ford Hospital, Division of Plastic Surgery, 2799 West Grand Blvd., Detroit, MI 48202.

Copyright (c) by The Wound Healing Society.

$1067-1927 / 95 \$ 3.00+0 \quad 36 / 1 / 62723$

\begin{tabular}{|ll|}
\hline IFN & Interferon \\
TGF- $\beta_{1}$ & Transforming growth factor- $\beta_{1}$ \\
\hline
\end{tabular}

human skin wounds, the healing process rapidly restores barrier function by epithelial proliferation and develops close to normal tensile strength by collagen synthesis and maturation.

Sometimes, the cellular processes contributing to repair become unregulated. A potential result is excess matrix synthesis, which results in excessive scarring. The adult wound that heals with excessive scar and the fetal wound that heals with no scar represent extremes of common fundamental processes of cell proliferation and extracellular matrix production and may reflect differences in regulatory function.

Hypertrophic scars and keloids have likely been present as long as human beings have been wounded. Abnormal scarring is mentioned in the Smith Papyrus of 2500 and 3000 B.C. ${ }^{1}$ Keloid formation is depicted in a 13th century Yoruba sculpture from West Nigeria. In 1816, Alibert first proposed the word keloid to differentiate these scar excrescences from cancerous tumors. ${ }^{2}$ The Greek word khele, meaning crab claw, is the root of the word describing the small claw-like projections of severe scarring extending beyond the original wound border into normal tissue. ${ }^{3}$ 


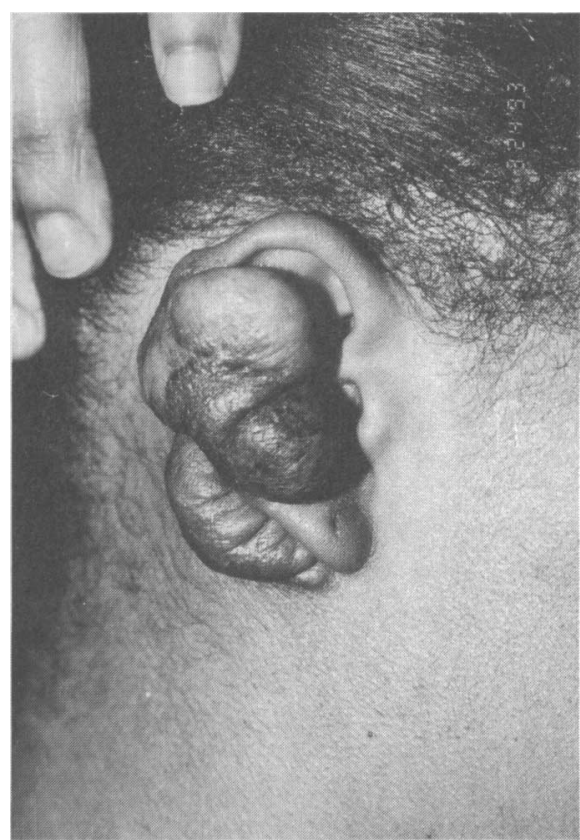

Figure 1 Earlobe keloid arising along the helical rim from earring puncture. Note the earlobe puncture site uninvolved by keloid.

\section{CLINICAL PRESENTATION}

Hypertrophic scars and keloids occur in $5 \%$ to $15 \%$ of wounds, and present a 5- to 15-fold higher risk to dark-skinned people. ${ }^{4-6}$ The clinical distinction is that hypertrophic scars remain within the borders of the original scar, whereas keloids extend beyond the original scar margins. ${ }^{7}$ Certain populations are more prone to excessive scarring than others. Dark-skinned patients between the ages of 2 and 40 years have an increased risk of the development of hypertrophic scars or keloids. However, patients in whom keloids or hypertrophic scars form during their childhood or teenage years may not exhibit this tendency later in life. ${ }^{8,9}$ Regional susceptibility to abnormal scars is recognized. Wounds crossing skin tension lines, in thick skin or in characteristic locations such as the presternal and deltoid regions of the trunk and earlobes, are prone to abnormal scarring (Figures 1 and 2). Some locations such as genitalia, eyelids, palms of the hand, and soles of the feet almost never develop abnormal scars. ${ }^{8}$

Keloid formation occurs mainly in parts of the body where the concentration of melanocytes is greatest, as well as during times of physiologic hyperactivity in the pituitary such as during puberty and pregnancy. ${ }^{10}$ Keloids are not limited to the skin and, though uncommon, have been reported on the cornea. ${ }^{11}$ Many

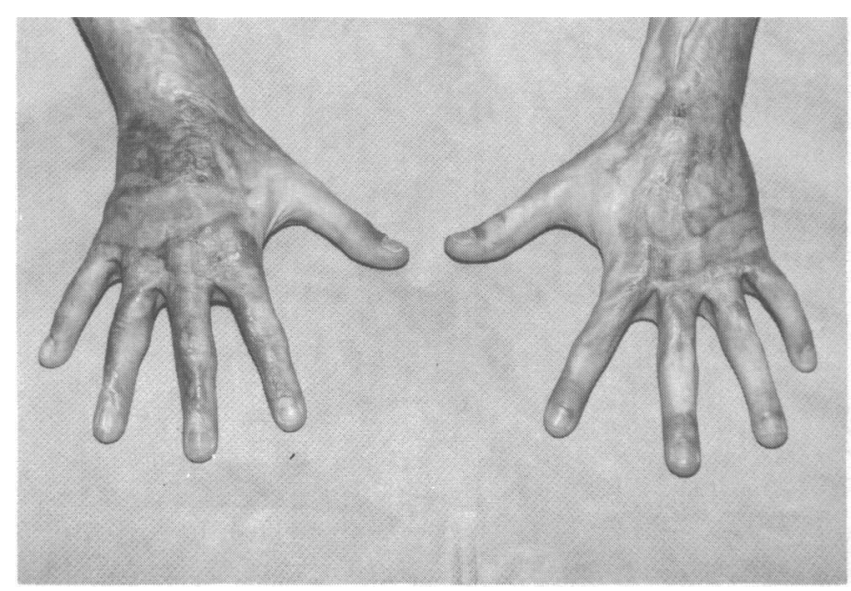

Figure 2 Hypertrophic scar formation affer burns is most marked on the dorsal aspect of the second and third web spaces in this patient.

authors have recognized a familial tendency in keloid formation. ${ }^{12-14}$

The time interval between injury and abnormal scar formation is variable. Hypertrophic scars generally begin to develop in the weeks after injury, whereas keloids may develop up to 1 year later. These scars are raised, nodular, pruritic, and sometimes painful. Patients with hypertrophic scar may seek a surgeon's attention for reasons such as local pain, itching, mass effect, chronic superficial skin breakdown, or unsightly appearance. In addition, function may be compromised when hypertrophic scarring occurs across a joint, creating flexion contractures. In patients with keloid, unsightly appearance, pruritus, or continued growth may result in a consultation for plastic surgery. Hypertrophic scars appear hyperemic, and Ehrlich and Kelly have documented elevated blood flow in hypertrophic scars as long as a year after healing. ${ }^{15}$ Deitch et al. ${ }^{16}$ noted that wounds with prolonged initial healing have a much greater propensity to form hypertrophic scar. This finding suggests a relationship in which a disordered repair scheme results in disordered healing. Hypertrophic scars may subside, whereas keloids generally do not. ${ }^{3}$ Rudolph has discussed clinical differences among widespread scars, hypertrophic scars, and keloids. ${ }^{17}$

\section{HISTOLOGIC ANALYSIS}

Attempts have been made to histologically distinguish hypertrophic scars from keloids. The differences are subtle and have been summarized in previous works. ${ }^{4,10}$ Keloids and hypertrophic scars differ from normal skin and normal scar by their rich vasculature, 
Table 1. Biochemical alterations associated with excessive scar formation

\begin{tabular}{ll}
\hline \multicolumn{1}{c}{ Molecule } & \multicolumn{1}{c}{ Finding } \\
\hline Prolyl hydroxylase & Activity K $>$ HTS $>$ NL \\
Collagen (total) & Synthesis K $>$ HTS $>$ NL \\
& Crosslinks NL $>$ K \\
Collagen (type III) & K NL \\
Collagenase & Activity K $>$ HTS $>$ NL \\
Chondroitin-4-sulfate & Content K,HTS $>$ NL \\
Glycosaminoglycans & Content HTS $>$ NL \\
Fibronectin & Synthesis K $>$ NL \\
& Receptor expression K $>$ NL \\
Hyaluronic acid & Degradation NL $>$ HTS \\
\hline
\end{tabular}

$K$, Keloid; HTS, hypertrophic scar; $N L$, normal.

high mesenchymal density, and thickened epidermal layer. Collagen fibers are organized in swirls. Few macrophages are present, whereas some lymphocytes and eosinophils are found. ${ }^{10}$ Histologic criteria characteristic of keloids, not hypertrophic scar, include the presence of broad eosinophilic refractive hyaline-like collagen fibers. ${ }^{4}$ Mucinous ground substance is abundant in keloids, but fibroblast density is less than that in hypertrophic scars. Scanning electron microscopy shows morphologic differences. The collagen weave in hypertrophic scars is different from that seen in normal skin or mature scar. Collagen bundles are flatter and less clearly demarcated, whereas fibers are loosely arrayed in a wavy pattern, fragmented, and shortened. The ultrastructure of keloids show even less organization. Their fibers are larger and more irregular, and their interfibrillar distance is less than that seen in hypertrophic scars. Discrete collagen bundles are virtually nonexistent, and fibers are randomly oriented to the epithelial surface.

The collagen nodule has been identified as a distinguishing structural unit between hypertrophic scar and keloid. ${ }^{18}$ The nodule, which is absent from mature scars, contains a high density of fibroblasts and unidirectional collagen fibrils aligned in a highly stressed orientation. Microvessels encircle the main body of the nodule as a knot; few appear within it.

Most microvessels in keloids and hypertrophic scars are partially or fully occluded, apparently owing to an excess of endothelial cells. Perivascular satellite cells, some of which share a similar structure to myofibroblasts, are also present. ${ }^{19}$

\section{PATHOGENESIS}

The cause of excessive scarring is multifactorial, and various causal theories of heredity, ischemia, mechani- cal stretch, and hormonal, immune, or inflammatory mechanisms have been suggested. ${ }^{3}$ Because the cause of abnormal scars is multifactorial, emphasis should be placed on understanding the final common cellular pathways which are manifest as a prolongation of the proliferative phase of wound healing. The clinical association of delayed wound healing and abnormal scar formation suggests that disruption of the normal healing cascade may result in abnormal wound healing. The following sections focus on specific alterations in cellular biochemistry, molecular biology including growth factors, and immunology that have been noted in keloids and hypertrophic scar.

\section{BIOCHEMISTRY}

Biochemical differences have been found in studies of abnormal scars, mature scars, and normal skin (Table 1). Collagen synthesis, as measured by prolyl hydroxylase activity, is significantly higher in keloids than in hypertrophic scars, and both are higher than in normal skin. ${ }^{22}$ Ala-rokko, Rintala, and Savolainen ${ }^{23}$ showed keloid prolyl hydroxylase activity to be significantly greater than that found in normal control skin. Collagen synthesis in keloids is approximately 20 times greater than that in normal unscarred skin and three times greater than that found in hypertrophic scar. ${ }^{22}$ Normal scar and skin adjacent to normal scar do not have significantly different rates of collagen synthesis. Craig, Schofield, and Jackson ${ }^{24,25}$ found the rate of collagen synthesis in keloids and hypertrophic scars fall to normal levels 2 to 3 years after injury. Cohen ${ }^{22}$ and Harris $^{26}$ and their associates noted increased soluble collagen in keloid scars, suggesting increased collagen synthesis, increased degradation, or decreased crosslinking. Knapp, Daniels, and Kaplan ${ }^{27}$ observed that normal skin, like mature scar, had proportionally greater content of highly cross-linked collagen than that found in keloids. This finding is not due to differences in lysyl oxidase, the enzyme crucial to cross-linking. Although these results are somewhat conflicting, these studies suggest intrinsic increases in collagen synthesis by scar tissues. The differences may be due to the fact that the samples were not all normalized to cell number and were obtained at different time periods after the initial wound. Garner et al. ${ }^{28}$ studied ascorbate-induced collagen synthesis by hypertrophic scar and normal dermal fibroblasts, matched by patient and derived from clinically active scars. The hypertrophic scar fibroblasts showed a significant increase in collagen synthesis. The findings of immature matrix suggest that keloids have a 
prolongation of the fibroplasia phase of wound healing and do not progress normally into the subsequent remodeling phase.

Collagenase activity in keloids, hypertrophic scars, and mature scars has been shown to be greater than that found in normal skin. Keloids show 14 times as much collagenase activity as does normal scar, whereas hypertrophic scar showed four times as much enzyme activity. ${ }^{29,30}$ In spite of increased potential degradative activity, a disproportionate increase in collagen synthesis might lead to net deposition of extracellular matrix and scar. Diegelmann, Bryant, and Cohen ${ }^{31}$ described the presence of the plasma proteins alpha I antitrypsin and alpha II macroglobulin within the interstitial space of abnormal scars. These serum proteinase inhibitors are thought to inhibit degradation of connective tissue. Linares and Larson ${ }^{32}$ have shown that collagen fibers coated with chondroitin-4-sulfate are resistant to digestion by collagenase. The overabundance of chondroitin-4-sulfate shown by Kischer ${ }^{33}$ and Shetlar ${ }^{34}$ and their associates may contribute to the net deposition of collagen in both keloids and hypertrophic scars.

Fibronectin is an important extracellular matrix molecule prevalent in early wound healing which later assumes a lesser role as fibroplasia supervenes. Keloid fibroblasts accumulate more cytoplasmic and cell surface-associated fibronectin than do normal fibroblasts. Babu, Diegelmann, and Oliver ${ }^{35}$ observed a onefold to fourfold increase in the rate of fibronectin biosynthesis relative to that in normal cells, which could be accounted for at the transcriptional level. Net accumulation of fibronectin in these fibroblasts may cause elevated fibronectin levels within keloid lesions. The fibronectin receptor (the $\alpha 5 \beta 1$ integrin heterodimer) was also noted to be increased within the keloid cells relative to normal cells. The combination of increased synthesis of fibronectin and increased expression of its receptor suggests lack of an inhibitory signal within the temporal sequence of wound healing and may contribute to the continued generation of extracellular matrix by means of integrin signaling to mesenchymal cells. Hyaluronic acid, an important constituent of the extracellular matrix, accumulates in fibrotic disorders and is catabolized less effectively by hypertrophic scar fibroblasts than by normal controls. ${ }^{36}$ This situation may be the result of a global increase in protein synthesis. The implications of an increase in hyaluronic acid and fibronectin is unclear because the extracellular matrix in fetal wounds is also rich in hyaluronic acid and fibronectin, with type III collagen being more abundant than type I collagen, yet those wounds ultimately heal with scant matrix deposition.
Table II. Patterns of gene expression present in excessive scar formation

\begin{tabular}{ll}
\hline \multicolumn{1}{c}{ Gene } & \multicolumn{1}{c}{ Finding } \\
\hline Type I collagen & Expression K,HTS $>$ NL \\
& Localized near K blood vessels \\
Type III collagen & Expression K $>$ NL, HTS $>$ NL \\
Type IV collagen & Not expressed by K \\
Type V collagen & Expressed by K \\
Type VI collagen & Localized in K papillary dermis \\
TGF- $\beta_{1}$ & Localized near K blood vessels \\
& Expressed by HTS \\
\hline
\end{tabular}

$K$, Keloid; $H T S$, hypertrophic scar; $N L$, normal.

\section{Molecular biology}

Keloid tissues contain $32 \%$ type III collagen as compared with $21 \%$ type III collagen present in normal dermis. ${ }^{20}$ Cyanogen bromide-digested collagen peptides of keloids are similar to fetal cell digests. ${ }^{21}$ Type III collagen has been postulated to be important for stabilizing new matrix and providing scaffolding for further healing events. Di Cesare et al. ${ }^{20}$ point out that the presence of immaturely cross-linked type III collagen in keloids indicates a pathologic process in which extracellular matrix fails to mature and achieve normal stability. They conclude that the collagenous extracellular matrix in keloids fails to mature, restore its normal collagen composition, and attain stability through cross-linking as in normal skin.

Recent studies have begun to investigate gene expression in conditions of excessive scarring (Table 2). Cultured fibroblasts from keloids studied by Uitto et al. ${ }^{37}$ compared site-matched skin fibroblasts of healthy age-matched patients. They noted that type I collagen gene expression was enhanced in keloid fibroblast cultures compared with controls. In addition, they noted differences in the ratio of type I to type III procollagen messenger RNAs. Keloid fibroblasts expressed these mRNAs in a 22:1 ratio (compared to a 6:1 ratio in controls) as a result of increased type I procollagen expression without alteration of type III procollagen mRNA expression. They concluded that the expression of type I procollagen may be selectively enhanced in keloid fibroblast cultures. The $22: 1$ ratio of type I/type III procollagen mRNA species does not correlate to the subsequent protein production, which may suggest posttranscriptional alterations of the type I procollagen mRNA or an increase in type I collagenolysis.

Uitto and associates further assessed type I procollagen gene copy number and found no evidence of gene amplification, therefore suggesting that the increase in type I procollagen mRNA occurs at the transcriptional level. ${ }^{37}$ Friedman et al. ${ }^{38}$ also studied procollagen gene 
expression in hypertrophic scar-cultured fibroblasts, noting increased amounts of collagen I mRNA and similarly high transcription rates of that gene in both fibroblast types. It is noteworthy that the procollagen type I/type III mRNA ratio found in keloids was much higher than that in hypertrophic scars. The authors speculated that this difference is due to posttranscriptional control of procollagen I mRNA in hypertrophic scar but not in keloids. ${ }^{38}$ Ala-Kokko, Rintala, and Savolainen ${ }^{23}$ also correlated procollagen production to expression of type I and type III procollagen mRNAs but did not detect overexpression of type I and type III procollagen mRNA compared with controls. It is noteworthy that the experiments of Ala-Kokko and associates were carried out in white patients whose keloid fibroblasts may produce less collagen. The age of the lesions studied is also an important factor. AlaKokko and associates also noted expression of type $\mathrm{V}$ procollagen mRNA as well. ${ }^{23}$

Recently, Peltonen et al. ${ }^{39}$ were able to spatially localize gene expression within keloids using in situ hybridization techniques. Type I procollagen gene expression was detected along the expanding border of the keloid lesion. The central portion of the lesions characterized by thick coarse collagen bundles did not show active type I procollagen gene expression. Further within keloid lesions, numerous small blood vessels were often surrounded by fibroblasts actively expressing type I procollagen genes. Localization of type III procollagen showed minimal labeling, suggesting heterogeneity of expression of this gene within keloid lesions. The authors speculated that type III procollagen expression may be a transient phenomena during the temporal development of a keloid lesion. Lee $^{40}$ also detected type I and III but not type IV procollagen gene expression in some fibroblasts from keloid tissue by in situ hybridization and speculated that clonal subpopulations are largely responsible for procollagen production. Sollberg, Peltonen, and Uitto ${ }^{41}$ also noted that type VI procollagen mRNA was found localized along blood vessels similar to type I collagen mRNA but its distribution differed in that papillary dermis also actively expressed the type VI procollagen gene, an area devoid of type I collagen gene expression. Type VI collagen has been suggested to play a role in the organization of the extracellular matrix. These results point out the heterogeneity of gene expression within the temporal and topographic domains of an evolving keloid lesion.

Sollberg, Peltonen, and Uitto ${ }^{41}$ noted the proximity of areas of active procollagen gene expression to blood vessels and suggested the possibility that vascular damage may be one of the early events leading to keloid formation. They colocalized type I procollagen mRNA with factor-8 surface antigen expression. These findings indicated that endothelium is capable of expressing type I procollagen genes and that the endothelial cells may contribute to the fibrotic keloid.

Additional insight into keloid cells has been derived from keloid cell cultures. Fibroblasts from keloids were noted to show similar growth kinetics to those found in normal skin and normal scar. ${ }^{42,43}$ However, Russell and $\mathrm{Witt}^{43}$ found that keloid cells were less demanding than normal cells with regard to serum and growth factor requirements and grew to higher densities. ${ }^{44}$ They postulated that this reduced growth factor requirement could explain the exuberant growth of keloid into tumorlike masses. Harper ${ }^{45}$ showed additional in vitro differences in keloid fibroblast lines when contrasted to normal fibroblasts. He noted that the in vitro life span of a keloid fibroblast was $31 \%$ shorter than that in normal controls. In his studies, keloid fibroblasts reached a lower cell density than did their normal counterparts. These studies did not stratify keloids into age or region. Indeed, fibroblasts isolated from different levels of the dermis, from the leading edge versus the center, or from early keloids versus late keloids could exhibit different growth properties and culture. The same observations may also hold for hypertrophic scar fibroblasts. Bertolami, Berg, and Messadi $^{36}$ observed altered growth kinetics in hypertrophic scar fibroblasts, noting a 69-hour doubling time compared with 40 hours for control normal fibroblasts.

\section{GROWTH FACTORS}

The role of growth factors in the formation of abnormal scar remains undetermined. Growth factors may profoundly influence multiple pathways involved in cell proliferation, extracellular matrix production, and degradation. Peltonen et al. ${ }^{39}$ showed the presence of transforming growth factor- $\beta_{1}\left(\mathrm{TGF}-\beta_{1}\right)$ protein and messenger RNA in areas of keloid activity expressing type I and type VI procollagen genes (Figure 3 ). They speculated that TGF- $\beta_{1}$ gene expression by neovascular endothelial cells may activate adjacent fibroblasts to express additional TGF- $\beta$, as well as enhance procollagen gene expression.

An altered cellular response to growth factors has been used to define fibroblast phenotypes within hypertrophic scars. ${ }^{28}$ Hypertrophic scar-derived fibroblasts showed decreased proliferation in response to epidermal growth factor and fetal bovine serum but not to tumor necrosis factor alpha or platelet-derived 
growth factor. Although normal dermal fibroblasts responded to TGF- $\beta$ with a significant elevation of collagen synthesis, the elevated rate of collagen synthesis by hypertrophic scar fibroblasts was not increased further by TGF- $\beta_{1}$ stimulation.

Tan and Peltonen ${ }^{46}$ noted a decrease in collagen synthesis as measured as hydroxy/proline synthesis by keloid fibroblast cultures that had endothelial cell growth factor and heparin added to the cultures. This inhibition was noted to occur at the transcription level. Tan et al. ${ }^{47}$ also studied regulation of collagen and proteoglycan expression in keloid fibroblasts in vitro and noted that fibroblast growth factor treatment produced similar responses in keloids and normal dermal fibroblast control cells. Interferon (IFN) is a factor with potential therapeutic benefit for excessive scars. Preliminary data from Sahara et al. ${ }^{48}$ show IFN- $\alpha_{2 \beta}$-mediated suppression of scar fibroblast contraction of collagen gels in vitro. Treatment with this agent has also been shown to normalize keloid collagen, glycosaminoglycan, and collagenase production in vitro. ${ }^{49}$ IFN- $\gamma$ also has been shown to decrease cell replication and alpha smooth muscle actin expression in hypertrophic scar fibroblasts in vitro. ${ }^{50}$ Tredget et al. ${ }^{51}$ noted IFN- $\alpha_{2 \beta}-$ mediated suppression of types I and III procollagen mRNA and protein production by hypertrophic scar fibroblasts in vitro.

\section{IMMUNOLOGY AND GENETICS}

Alterations in immune cells and immunologic function have been suggested as causes for excessive scarring. Keloids may be the result of an immune reaction to skin antigens, sebum, melanin, blood products, or foreign bodies. ${ }^{3}$ Differences in immunoglobulin levels have been shown within keloid scars. ${ }^{52}$ Inflammatory cells found within abnormal scar may play important regulatory roles in the fibrogenic process ${ }^{53}$ In particular, mast cells may play a regulatory role in abnormal scars and have been found interspersed along dermal collagen bundles in keloids. ${ }^{54,55}$ Histamine levels are increased in keloid tissue, which may enhance the formation of collagen. Histamine is also a competitive inhibitor of lysyl oxidase, which can explain the abnormal cross-linkage formation shown in collagen and the increased amounts of soluble collagen in keloids. $^{26}$

Castagnoli et al. ${ }^{56}$ recently characterized hypertrophic scars and noted dense infiltrates of interleukin-2 receptor-positive cells and abundant Langerhans cells in epidermis and dermis; this suggests an important role of immunologic mechanisms in

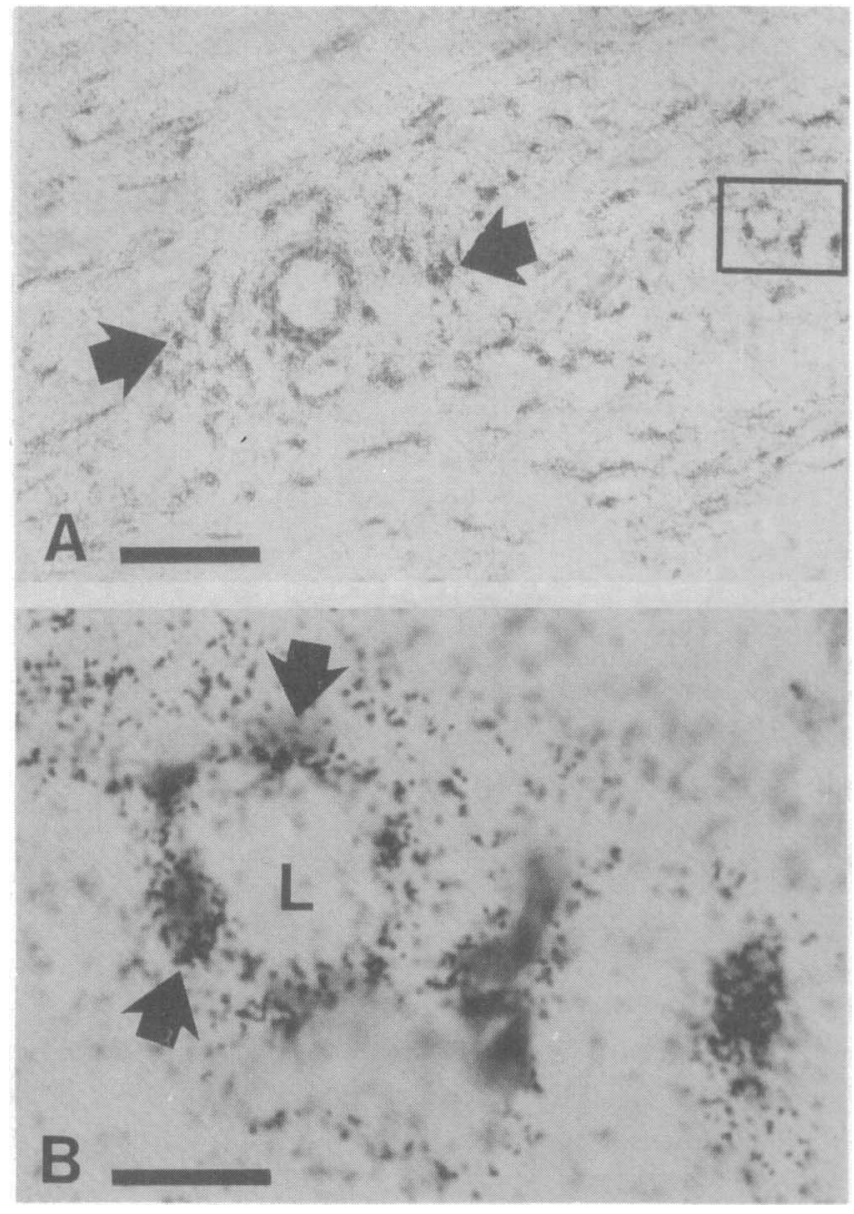

Figure 3 Demonstration of TGF- $\beta_{1}$ gene expression in keloid tissue. In situ hybridizations were performed with a single-stranded CRNA probe. Note that the autoradiographic grains, representative of (32P) CRNA-mRNA hybrids, are associated with (A) fibroblasts (arrows), and with (B) endothelial cells of capillaries (arrows). $L$ denotes the lumen of the blood vessel. The area outlined by the box $(A)$ is enlarged in B. Bars: A, $100 \mu \mathrm{m} ; \mathbf{B}, 20 \mu \mathrm{m}$. Reprinted with permission of Elsevier Science Inc. from Peltonen et al., The Journal of Investigative Dermatology, vol. 97, p. 247. Copyright 1991 by the Society for Investigative Dermatology, Inc.

hypertrophic scar formation. It is noteworthy that fibroblasts and keratinocytes were observed to express class II antigens in hypertrophic scars, but whether they are involved in antigen presentation is a point of speculation. The T-cell population may play an important role in pathogenesis of abnormal scars because persistent perivascular lymphocytes have been seen in abnormal scars associated with increased collagen deposition. ${ }^{57}$ Conversely, mice depleted of T-cells show depressed wound healing ability as assessed by bone breaking strength and collagen synthesis. ${ }^{58} \mathrm{McCauley}$ et al. ${ }^{59}$ established differences in cytokine production by peripheral blood mononuclear cells present in keloid versus control patients. They suggested that an altered 


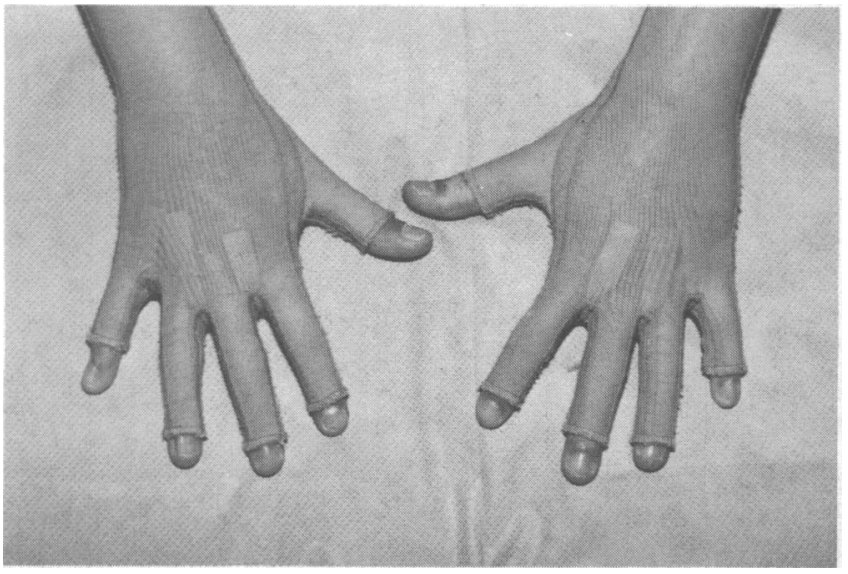

Figure 4 Hypertrophic scarring from burns treated with a combination of compressive garments and silicone gel placed in the dorsal web spaces (same patient as seen in Figure 2).

immunoregulation by inflammatory cells rather than primary fibroblast alterations play a significant role in keloid formation.

A genetic predisposition for keloid formation has been recognized, particularly in individuals with multiple lesions, with both autosomal dominant and recessive modes of inheritance reported. ${ }^{12,13}$ The prevalence of several HLA-B and HLA-D loci have been shown at increased levels in patients with keloid. ${ }^{60}$ The human leukocyte antigen-DR beta 16 allogenotype has been associated with a 12-fold increased risk for hypertrophic scar formation. ${ }^{61}$

\section{THERAPY}

Optimal therapy for excessive scarring has yet to be established. Treatment is empiric, and all modalities are plagued by high recurrence rates, especially in patients with keloid. Current therapy for keloids consists of surgical excision or nonsurgical treatment including radiotherapy and corticosteroid injection. This subject was recently reviewed by Lawrence, ${ }^{3}$ who compared relative efficiencies of the various treatments for keloids. DNA analysis has been used to predict clinical behavior of soft tissue tumors, ${ }^{62}$ and aneuploid keloids have been noted to have a greater propensity for recurrence. ${ }^{63}$ Optimal treatment of keloids may be guided by recurrence potential, with more modalities combined for the most difficult lesions.

Treatment for hypertrophic scars similarly involves surgical excision and nonsurgical therapy. Surgical treatment focuses on reduction of inflammation through early wound closure and on alteration of biochemical forces on the scar through interposition of unscarred skin along tension lines. Among nonsurgical therapies for excessive scars, use of topical silicone, ${ }^{64}$ compression therapy, ${ }^{65}$ and steroid injections ${ }^{17}$ are of documented benefit (Figure 4).

The abundance of empiric treatment modalities for excessive scarring attest to the lack of understanding of the pathogenesis of this clinical condition. Treatment strategies directed toward specific alterations in the keloid or hypertrophic scar cell biology will offer the best choice for therapeutic efficacy. For example, blockade of a growth factor with known matrixstimulating properties such as TGF- $\beta$ would reduce accumulation of scar tissue. Shah, Foreman, and Ferguson $^{66}$ recently showed that scar formation in normal incisional murine wounds could be limited by antibodies blocking TGF- $\beta .{ }^{66}$ There have also been promising trials with IFN in the treatment of excessive scar. Uncontrolled trials with the use of IFN- $\gamma$ in the treatment of hypertrophic scarring ${ }^{67}$ and IFN- $\alpha_{2 \beta}$ treatment of keloids ${ }^{49}$ suggest beneficial effects on resolution of these lesions. A small controlled trial of keloid treatment with intralesional injection of IFN- $\gamma$ showed significant reduction in lesion height. ${ }^{68} \mathrm{IFN}-\gamma$ also was effective in reducing symptoms and scar size in patients with hypertrophic scar. ${ }^{50}$

At the present time, no simple cure exists for excessive scarring. It is also difficult to postulate a discrete mechanism responsible for this type of scar formation. Recent advances in molecular biology and biochemistry have provided some detailed descriptive information but have not provided a unifying hypothesis. Overall, hypertrophic scarring seems to be the result of disordered normal healing, a process caused by intrinsically normal cells reacting to exogenous stimuli such as prolonged inflammation or biochemical force. Keloids, on the other hand, may arise in the absence of significant exogenous stimuli and, as such, may be considered to have some endogenous tendency toward excessive scar formation. In both cases, a multifactorial origin is likely. It seems reasonable to prevent prolonged exogenous stimulation of a healing wound and to treat excessive scar formation with combined modalities. Specific endogenous factors driving keloid scar formation may be identified, and specific pharmacotherapy can then be designed to limit those processes. These therapies will ultimately promote degradation or limit production of extracellular matrix within the scar. Treatment strategies targeting specific growth factor receptors or matrix genes may ultimately 
provide the most useful therapy for excessive scar formation.

\section{REFERENCES}

1. Breasted JH. The Edwin Smith surgical papyrus, hieroglyphic text translation and commentary. Vol 1. Chicago: University of Chicago Press, 1930:403-6.

2. Alibert JLM. Quelques recherches sur la cheloide. Mem Soc Med d'Emul 1817;8:744.

3. Lawrence WT. In search of the optimal treatment of keloids: report of a series and a review of the literature. Ann Plast Surg 1991;27:164-78.

4. Cosman B, Crikelair GF, Ju DM, Gaulin JC, Lattes R. The surgical treatment of keloids. Plast Reconstr Surg 1961;27:33558.

5. Alhady SM, Sivanantharajah K. Keloids in various races: a review of 175 cases. Plast Reconstr Surg 1969;44:564-6.

6. Koonin AJ. The aetiology of keloids: a review of the literature and a new hypothesis. South Afr Med J 1964;38:913-6.

7. Peacock EE Jr, Madden JW, Trier WC. Biologic basis for the treatment of keloids and hypertrophic scars. South Med J 1970;63:755-9.

8. Datubo-Brown D. Keloids: a review of the literature. Br J Plast Surg 1990;43:70-7.

9. Ketchum LD, Cohen IK, Masters FW. Hypertrophic scars and keloids: a collective review. Plast Reconstr Surg 1974;53:140-54.

10. Rockwell WB, Cohen IK, Ehrlich HP. Keloids and hypertrophic scars: a comprehensive review. Plast Reconstr Surg 1989;84: 827-37.

11. Shukla IM, Arora MP, Aoroa MM. Corneal keloids. Indian J Ophthal 1975;23:18-21.

12. Omo-Dare P. Genetic studies on keloid. J Natl Med Assoc 1975;67:428-32.

13. Bloom $D$. Heredity of keloids: review of the literature and report of a family with multiple keloids in five generations. NY State J Med 1956;56:511-9.

14. Murray JC, Pollack SV, Pinnell SR. Keloids: a review. J Am Acad Dermatol 1981;4:461-70.

15. Ehrlich HP, Kelly SF. Hypertrophic scar: an interruption in the remodeling of repair - a laser doppler blood flow study. Plast Reconstr Surg 1992;90:993-8.

16. Deitch EA, Wheelan TM, Rose MP, Clothier J, Cottes J. Hypertrophic burn scars: analysis of variables. J Trauma 1983;23:895-8.

17. Rudolph $\mathrm{R}$. Wide spread scars, hypertrophic scars, and keloids. Clin Plast Surg 1987;14:253-60.

18. Kischer CW, Brody GS. Structure of the collagen nodule from hypertrophic scars and keloids. Scanning Microsc 1981;3:371-6.

19. Kischer CW, Theis AC, Chvapil M. Perivascular myofibroblasts and microvascular occlusion in hypertrophic scar and keloids. Hum Pathol 1982;13:819-24.

20. Di Cesare PE, Cheung DT, Perelman N, Libaw E, Peng L, Nimni ME. Alteration of collagen composition and crosslinking in keloid tissues. Matrix 1990;10:172-8.

21. Weber L, Miegel WN, Spier W. Collagen polymorphism in pathological human scars. Arch Dermatol Res 1979;261:63-71.

22. Cohen IK, Diegelmann RF, Keiser HR. Collagen metabolism in keloid and hypertrophic scar. Surg Forum 1971;22:488-9.

23. Ala-Kokko L, Rintala A, Savolainen ER. Collagen gene expression in keloids: analysis of collagen metabolism and type I, III, IV and $\mathrm{V}$ procollagen mRNAs in keloid tissue and keloid fibroblast cultures. J Invest Dermatol 1987;89:238-44.

24. Craig RDP, Schofield JD, Jackson DS. Collagen biosynthesis in normal and hypertrophic scars and keloids as a function of the duration of the scar. Br J Surg 1975;62:741-4.
25. Craig RDP, Schofield JD, Jackson DS. Collagen biosynthesis in normal human skin, normal and hypertrophic scar and keloid. Eur J Clin Invest 1975;5:69-72.

26. Harris ED Jr, Sjoerdsma A. Collagen profile in various clinical conditions. Lancet 1966;2:707-11.

27. Knapp TR, Daniels JR, Kaplan EN. Pathologic scar formation. Am J Pathol 1977;86:47-70.

28. Garner W, Karmiol S, Rodriguez J, Smith D Jr, Phan S. Phenotypic differences in cytokine responsiveness of hypertrophic scar vs. normal dermal fibroblasts. J Invest Derm 1993;101:875-9.

29. Craig $P$. Collagenase activity in cutaneous scars. Hand $1983 ; 5$ : 239-41.

30. McCoy BJ, Cohen IK. Collagenase in keloid biopsies and fibroblasts. Connect Tissue Res 1982; 9:181-5.

31. Diegelmann RF, Bryant CP, Cohen IK. Tissue alpha-globulins in keloid formation. Plast Reconstr Surg 1977;59:418-23.

32. Linares HA, Larson DL. Proteoglycans and collagenase in hypertrophic scar formation. Plast Reconstr Surg 1978;62:589-93.

33. Kischer CW, Shetlar MR. Collagen and mucopolysaccharides in the hypertrophic scar. Connect Tissue Res 1974;2:205-13.

34. Shetlar MR, Shetlar CL, Kischer CW, Pindur J. Implants of keloid and hypertrophic scars into the athymic nude mouse: changes in the glycosaminoglycans of the implants. Connect Tissue Res 1991;26:23-36.

35. Babu M, Diegelmann $R$, Oliver N. Fibronectin is overproduced by keloid fibroblasts during abnormal wound healing. Mol Cell Biol 1989;9:1642-50.

36. Bertolami CN, Berg S, Messadi DV. Binding and internalization of hyaluronate by human cutaneous fibroblasts. Matrix 1992; 11:11-21.

37. Uitto J, Perejda AJ, Abegel RP, Chu M-L, Ramirez F. Altered steady-state ratio of type I/III procollagen mRNAs correlates with selectively increased type I procollagen biosynthesis in cultured keloid fibroblasts. Proc Natl Acad Sci U S A 1985;82: 5935-9.

38. Friedman DW, Boyd CD, Mackenzie JW, Norton P, Olson RM, Deak SB. Regulation of collagen gene expression in keloids and hypertrophic scars. J Surg Res 1993;55:214-22.

39. Peltonen J, Hsiao LL, Jaakkola S. Sollberg S, Aumailley M, Timpl R, Chu M, Uitto J. Activation of collagen gene expression in keloids: co-localization of type $I$ and VI collagen and transforming growth factor-beta 1 mRNA. J Invest Derm 1991;97:240-8.

40. Lee KJ. Gene expression in keloids by in situ hybridization. J Acad Derm 1993;27:213-6.

41. Sollberg S, Peltonen J, Uitto J. Combined use in situ hybridization and unlabeled antibody peroxidase antiperoxidase methods: simultaneous detection of type I procollagen mRNAs and factor VIII-related antigen epitopes in keloid tissue. Meth Lab Invest 1991;64:125-9.

42. Diegelmann RF, Cohen IK, McCoy BJ. Growth kinetics and collagen synthesis of normal skin, normal scar and keloid fibroblasts in vitro. J Cell Physiol 1979;98:341-6.

43. Russell JD, Witt WS. Cell size and growth characteristics of cultured fibroblasts isolated from normal and keloid tissues. Plast Reconstr Surg 1976;57:207-12.

44. Russell SB, Trupin KM, Rodriguez-Eaton S, Russell JD. Reduced growth factor requirements of keloid-derived fibroblasts may account for tumor growth. Proc Natl Acad Sci U S A 1988;85:587-91.

45. Harper RA. Keloid fibroblasts in culture: abnormal growth behavior and altered response to the epidermal growth factor. Cell Bio Intl Reports 1989;13:325-35.

46. Tan ML, Peltonen J. Endothelial cell growth factor and heparin regulate collagen gene expression in keloid fibroblasts. Biochem J 1991;278:863-9. 
47. Tan ML, Rouda S, Greenbaum S, Moore J, Fox J, Sollberg S. Acidic and basic growth factors down-regulate collagen gene expression in keloid fibroblasts. Am J Pathol 1993;142:463-70.

48. Sahara K, Kucukcelebi A, Ko F, Phillips L, Robson M. Suppression of in vitro proliferative scar fibroblast contraction by interferon alpha-2b. Wound ReP REG 1993;1:22-7.

49. Berman B, Duncan MR. Short-term keloid treatment in vitro with human interferon alpha-2 beta results in a selective and persistent normalization of keloidal fibroblast collagen, glycosaminoglycan and collagenase production. J Am Acad Dermatol 1989;21:694-702.

50. Pittet B, Rubbia-Brandt L, Desmouliere A, Sappino A, Roggero P, Guerret S, Grimaud J, Lacher R, Montandon D, Baggiani G. Effect of $\gamma$-interferon on the clinical and biologic evolution of hypertrophic scars and Dupuytren's disease: an open pilot study. Plast Reconstr Surg 1994;93:1224-35.

51. Tredget E, Shen Y, Forsyth C, Smith C, Liu G, Scott P, Ghahary A. The effect of interferon alpha-II beta on hypertrophic scar fibroblasts in vitro [Abstract]. Proceedings from the Second Annual Scientific Meeting of the Wound Healing Society, Richmond, Va., May 23-26, 1992:126.

52. Kischer CW, Shetlar MR, Shetlar CL, Chvapil M. Immunoglobulins and hypertrophic scars and keloids. Plast Reconstr Surg 1983;71:821-5.

53. Linares HA. Proteoglycan-lymphocyte association in the development of hypertrophic scars. Burns 1990;16:21-4.

54. Asoe-Hansen G. Endocrine control of connective tissue. J Med 1959;26:470-84.

55. Craig SS, Deblois G, Schwartz LB. Mast cells in human keloid, small intestine and lung by immunoperoxidase technique using a murine monoclonal antibody against tryptase. Am J Pathol 1986;124:427-35.

56. CaStagnoli C, Stella M, Magliacani G, Alasia ST, Richiardi R. Anomalous expression of HLA class II molecules on keratinocytes and fibroblasts in hypertropic scars consequent to thermal injury. Clin Exp Immunol 1990;82:350-4.

57. Barbul A. Role of the T-cell dependent immune system in wound healing. In: Hunt TK, Pines E, Barbul A, editors. Growth factors and other aspects of wound healing: biological and clinical application. New York: Alan R. Liss, 1988:161-75.

58. Piguet PF, Collart MA, Grau GE, Kapanci Y, Vassali P. Tumor necrosis factor/cachectin in plays a key role in bleomycininduced pneumopathy and fibrosis. J Exp Med 1989;170:655-63.

59. McCauley RL, Chopra V, Li Y-Y, Herndon DN, Robson MC. Altered cytokine production in black patients with keloids. J Clin Immunol 1992;12:300-8.

60. Nemeth AJ. Keloids and hypertrophic scars. J Dermatol Surg Oncol 1993;19:738-46.

61. Castagoli C, Peruccio D, Stella M, Magliacani G, Mazzola G, Amoroso A, Richiardi P. The HLA-DRB16 allogenotype constitutes a risk factor for, hypertrophic scarring. Human Immunol 1990;29:229-32.

62. Agarwal V, Greenbaum E, Wersto R, Koss LG. DNA ploidy of spindle cell soft tissue tumors and its relationship to histology and clinical outcome. Arch Pathol Lab Med 1991;115:558-62.

63. Gibson JS, Franklin RB, Buerk CA. Variability of DNA ploidy in keloid tissues and cell lines [Abstract]. Proceedings from the Second Annual Scientific Meeting of the Wound Healing Society, Richmond, Va., May 23-26, 1992:124.

64. Saweda $Y$, Stone K.Treatment of scars and keloids with a cream containing silicone oil. Br J Plast Surg 1990;43:683-8.

65. Ward RS. Pressure therapy for the control of hypertrophic scar formation after burn injury. J Burn Care Rehabil 1991;12:25762.

66. Shah M, Foreman DM, Ferguson MWJ. Control of scarring in adult wounds by neutralizing antibody to transforming growth factor beta. Lancet 1992;339:213-4.

67. Larrabee WF, East CA, Jaffe HS, Stephenson C, Peterson KE. Intralesional interferon gamma treatment for keloids and hypertrophic scars. Arch Otolaryngol Head Neck Surg 1990; 116:1159-62.

68. Granstein R, Rook A, Flotte T, Haas A, Gallo R, Jaffe H, Amento E. A controlled trial of intralesional recombinant interferon- $\gamma$ in the treatment of keloidal scarring. Arch Derm 1990;126:1295302.

\section{Availability of JouRNAL Back Issues}

As a service to our subscribers, copies of back issues of WOUND REPAIR AND REGENERATION are maintained and are available for purchase from the publisher, Mosby-Year Book, Inc., at a cost of $\$ 15.00$ per issue. The following quantity discounts are available: $25 \%$ off on quantities of 12 to 23 , and one third off on quantities of 24 or more. Please write to Mosby-Year Book, Inc., Subscription Services, 11830 Westline Industrial Drive, St. Louis, MO 63146-3318, or call (800)453-4351 or (314)453-4351 for information on availability of particular issues. If unavailable from the publisher, photocopies of complete issues are available from University Microfilms International, 300 N. Zeeb Rd., Ann Arbor, MI 48106 (313)761-4700. 